\title{
Doña Marina, otra vez. Las contradicciones de la propuesta de Inés M. Stranger en Malinche
}

IRIS DE BENITO MESA

Universitat de València

Resumen: La obra Malinche, de Inés M. Stranger, configura una propuesta de reescritura de la Malinche como figura mítica incorporada al imaginario cultural hispanoamericano, que perdura hasta la actualidad. Es común el empleo de esta figura en diversos autores contemporáneos que abordan cuestiones relativas a las identidades nacionales latinoamericanas en sus textos. Algunas autoras han utilizado, además, este personaje para elaborar una reescritura del mito con perspectiva crítica, en relación al modo en que este califica a un modelo de mujer indígena con toda una serie de significados negativos. La obra de Inés M. Stranger a la que se dedica el presente trabajo tiene unos presupuestos similares. El objetivo del estudio será el análisis crítico de esta obra, con el fin de dilucidar hasta qué punto la propuesta contiene una subversión crítica del personaje y en qué medida participa de otros discursos anteriores que privilegian la mirada occidental sobre la cultura indígena. Palabras clave: reescritura, mito, voz, traición, culpa.

\section{Doña Marina, again. The contradictions of the proposal of} Inés M. Stranger in Malinche

Abstract: Inés M. Stranger's Malinche makes up a rewriting proposal of Malinche, as it's a mythical figure that has been incorporated to latin american cultural imaginary. The use of this character is common in several contemporary authors who tackle, through their texts, matters relating to latin american national identities. As well, some other authors have used Malinche in order to make a critical rewriting, since this myth has become a negative model of indigenous women. Inés M. Stranger's narrative, to which this work refers, is locating within this set of ideas. The objective of this study is to critically analyse this narrative with a view to identify to what extent it makes a critical subversion of the character or if, in some sense, it participates in other old discourses that privilege West's look to indigenous cultures.

Keywords: rewriting, myth, voice, treason, blame. 


\section{INTRODUCCIÓN}

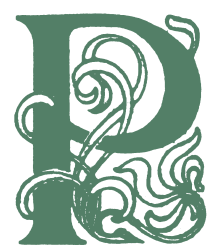

ara estudiar la reescritura contemporánea de un personaje histórico convertido en mito como es el de la Malinche, es necesaria, en un primer momento, la conceptualización de este referente en los diferentes discursos producidos desde la época de la Conquista de América. Si bien el personaje funcionó como símbolo en la configuración de identidades nacionales durante los procesos de independencia en América Latina en el siglo XIX, no por ello puede afirmarse que su figuración mítica surja en esta época. Deben plantearse cuestiones como la siguiente: la Malinche ha sido descrita y representada a través de ciertos discursos en los que ella jamás intervino de forma activa. Paradójicamente, poco sabemos de ella como personaje histórico, pues a pesar de que uno de los principales roles que se le atribuye es el de traductora e intérprete, las crónicas, como es el caso de la de Bernal Díaz del Castillo (2011), se refieren a ella por su papel al transmitir las palabras ajenas, y no ha pasado a la Historia testigo alguno de la enunciación de su subjetividad. En este sentido, es cierto que ocupó, como mujer indígena, un lugar entre las filas de Cortés que le otorgó cierto poder impensable para otras mujeres indígenas. Sin embargo, y salvando las distancias, dado que ese papel de intérprete no le permitió enunciar su subjetividad sino reproducir la voz de otros, podemos pensar en ella como sujeto subalterno, en la línea en que lo caracteriza Spivak (2009: 120-122), al que el acceso a la palabra le está restringido. Por su parte, Margo Glantz (2001) se preguntaría

¿Por qué, entonces, Marina, la de la voz, nunca es dueña del relato? Su discurso soslayado por la forma indirecta de su enunciación, se da por descontado, se vuelve, en suma, "un habla que no sabe lo que dice", porque es un habla que aparentemente solo repite lo que otros dicen. Su discurso [...] es el del otro o de los otros. La palabra no le pertenece.

Sobre esta base, es pertinente comenzar por plantear el proceso de la Conquista de América como una fundación de referentes desde la perspectiva occidental ${ }^{11}$ del conquistador, una "invención" en términos de O'Gorman (2006), a través de la cual se anularon todas las identidades culturales prece-

1 Se aborda la idea de "lo occidental" o de "occidente" en los términos que esboza Hall (1992:2). 
dentes. Así pues, si el colectivo indígena acaba relegado a la subalternidad, esta opresión fue doblemente ejercida sobre la mujer indígena. Es interesante pensar en la Conquista como un proceso de escritura sobre el Otro; pensemos en la imagen que dibujan las palabras de González Echevarría cuando afirma que "América Latina, como la novela, se creó en el archivo» (2000: 59), en el sentido en que fueron los archivos y las crónicas elementos claves para dicha fundación referencial. Respecto al concepto de «identificación», Stuart Hall (2003: 18) señala que esta «está sujeta al "juego" de la différance», y que por tanto necesita de «lo que queda fuera, su exterior consecutivo, para consolidar el proceso», lo que conduce al concepto de «afuera constitutivo» señalado por autores como Derrida (2014) o Butler $\left(2002^{2}\right)$. Es esta la línea en la que interpretamos la descripción del indígena como forma de construir y reafirmar, por parte del conquistador, la identidad del hombre occidental.

De cualquier modo, se plantean las nociones en torno a este periodo histórico como base para un acercamiento al texto, entendiendo que los procesos de construcción nacional anteriormente mencionados, y las producciones culturales que influyeron en ellos, interpelan constantemente a la Conquista como punto de partida problemático sobre el que situar un origen identitario. En este contexto, la Malinche se consagró como un determinado modelo de mujer ligado al concepto de traición, por la creencia de que fue partícipe de un engaño a su pueblo con el fin de colaborar en la que fue la definitiva victoria de Hernán Cortés sobre Tenochtitlán. Al respecto, C. González Hernández apunta lo siguiente:

[...] la historiografía nacionalista sobre la Conquista no intentará explicar las causas del triunfo de ésta, sino señalar a los culpables. La Malinche será la pieza clave que debe encajar en el rompecabezas de la identidad nacional, se convertirá en el chivo expiatorio sobre el que descargar todas las culpas. (2002:90)

Existen largos debates en torno a cuál fue exactamente el papel histórico de la Malinche, pero el foco de interés de este trabajo se centra más bien en cómo funciona como referente cultural mítico, dado que su entidad de personaje histórico escapa al alcance del estudio y no resulta funcional para los objetivos del mismo.

2 Traducido como "exterior constitutivo" en la edición consultada. 
Octavio Paz (1998), y algunos otros escritores como Rodolfo Usigli (1983) o Celestino Gorostiza (2004) siguen esta línea de pensamiento que consagra a la Malinche como un modelo negativo de mujer que se contrapondrá a la Virgen de Guadalupe; un binomio que guarda correspondencias con la contraposición de Eva y María en el relato bíblico y con algunos otros pares que han funcionado a lo largo de la Historia para catalogar a las mujeres en su dimensión positiva o negativa. Concretamente, en El laberinto de la soledad, Paz afirma que

Doña Marina se ha convertido en una figura que representa a las indias, fascinadas, violadas o seducidas por los españoles. Y del mismo modo que el niño no perdona a su madre que lo abandone para ir en busca de su padre, el pueblo mexicano no perdona su traición a la Malinche. (1998:35)

El fenómeno social conocido como "malinchismo", del que son representativas estas palabras de Paz, es caracterizado por Milagros Palma (1991) del siguiente modo:

Cada vez más se reactualiza la imagen de la traición encarnada en el mundo femenino, el "malinchismo" está a la orden del día para denunciar cualquier actitud "extranjerizante", por parte de mujeres sobre todo y de hombres. El "malinchismo" vendría a ser la actitud opuesta al nacionalismo cerrado, conservador que ha venido cultivando el mundo criollo y mestizo en América Latina frente al imperio norteamericano. Según la lógica de lo femenino/masculino, frente a este mundo del imperio que es masculino, los herederos de Cortés se feminizan, por su misma debilidad frente a esta relación de fuerzas. La consigna es no abrirse, quedarse cerrados, ser "machos" hasta el final como los estoicos aborígenes que murieron sin rendirse, dirá el mito. (1991: 146)

Sobre esta versión que en el presente trabajo llamaremos "clásica" del personaje, surgen a partir de la mitad del siglo veinte una serie de textos escritos por mujeres que toman este referente negativo, que las interpela de alguna forma como mujeres latinoamericanas, y llevan a cabo propuestas que retoman la figura mítica y dialogan con ella haciéndola funcionar de formas subversivas con resultados más o menos efectivos; entre estos trabajos contamos los de Rosario Castellanos (1975), Sabina Berman (1985), Elena Garro (1989), Lucía Guerra (2006), Laura Esquivel (2006) o Inés Stranger (2012), cuya obra aborda el análisis del presente trabajo. 


\section{ACERCA DE LA OBRA MALINCHE, DE INÉS M. STRANGER.}

Aunque la obra de Stranger sea una pieza teatral, este trabajo la estudia en su dimensión textual dada la imposibilidad de poder analizarla en términos de espectáculo ${ }^{3}$. Además, se trata de un texto muy narrativizado, y lo que serían acotaciones aportan información relevante a nuestro análisis dado que dan cuenta de la perspectiva de un narrador. Se trata de una obra escrita en 1992 (Lagoeiro, 2015: 194) y representada durante la última década del siglo veinte y los primeros años del presente ${ }^{4}$. A lo largo del relato se presenta una serie de atributos que remiten a la figuración mítica de la Malinche. En primer lugar, el tópico del enamoramiento hacia el conquistador, que aparece con frecuencia como forma de debilitar al personaje femenino $\mathrm{y}$, por otro lado, las nociones de traición y de culpa. El texto da pie, además, a tratar el modo en que este tipo de figuras míticas unidimensionalizan a la mujer y funcionan como esquema abarcador que anula la pluralidad y la diversidad.

Siempre tuve la sensación de que si habíamos sido y somos mestizos, de alguna manera nuestra madre indígena primigenia había sido una traidora, una Malinche. Pero si reconocemos que muchas fueron violadas, también hubo de alguna manera historias de amor (Bravo Elizondo, 1996: 90).

Estas palabras, pronunciadas por la autora en una entrevista en 1996, sintetizan muchos de los puntos clave de la obra cuyo análisis ocupa este trabajo. Se trata de una pieza teatral que construye una visión múltiple de la Malinche, es decir, en ella el significante Malinche se disemina en varios personajes que, a nuestro parecer, encarnan la multiplicidad de atributos que las distintas producciones discursivas han dado al personaje a lo largo de la Historia. Así, encontraremos a una Malinche "clásica", en la línea en que Octavio Paz la trata, que será la Hija Mayor de la familia; a varias Malinches enamoradas que construyen su modo de actuar sobre la base de la sentimentalidad; también hallaremos a la Malinche-madre encarnada en más de un personaje y, por último, a la no-Malinche hija, sobre la que se depositará una misión esperanzadora frente a la lacra que arrastran su madre y hermanas.

\footnotetext{
3 Aunque se trabaje la obra en su vertiente narrativa, es interesante tener en cuenta cómo, durante la segunda mitad del siglo XX, en el teatro mexicano, y en menor medida en otros países latinoamericanos, surgió una considerable cantidad de representaciones que incorporaban al personaje de la Malinche. Estas, incluyendo la obra de Stranger de que se ocupa este trabajo, son analizadas en su vertiente escénica por Albaladejo López (2016: 51-52).

4 Según datos la edición consultada (2012: 25), la obra Malinche. Cariño Malo. Tálamo (2007) recoge las tres obras teatrales de la autora producidas y llevadas a escena por la autora.
} 
Esta representación múltiple de la Malinche da, por un lado, cuenta de la diversidad de discursos que le han otorgado los distintos atributos que la configuran. Por otra parte, la asignación de los rasgos de la Malinche a todas las mujeres indígenas de la casa - la Hija Pequeña es mestiza - funciona como un mecanismo de generalización del esquema del personaje al referente de mujer-indígena cuyos presupuestos, como veremos, acabarán por no alejarse tanto de las palabras que Octavio Paz (1998) le dedica, ya citadas.

\subsection{Una caracterización a través de los espacios}

El texto distribuye el espacio de la acción en torno a dos polos muy marcados: dentro y fuera. El "adentro" será la casa en que conviven cinco mujeres, una madre y sus cuatro hijas ${ }^{5}$, mientras que el "afuera" quedará como un espacio indeterminado que se relaciona con la amenaza de la invasión, lo que remite a los hechos de la Conquista. En dicho espacio del "afuera", el exterior de la casa, es en el que se sitúan en principio los personajes masculinos, adscritos a la figura del conquistador. De este modo, el espacio de la casa, esto es, el ámbito de lo privado, se construye como el lugar en el que naturalmente habitan las mujeres y, no solo eso, sino que es también el espacio en el que se da la comunicación y entendimiento entre ellas.

Con ello, el hecho de que traspasen la línea que delimita el adentro marca el inicio de un conflicto. Así pues, Cuando la Hija Mayor marcha con el Capitán se desata el motivo de la traición y ello provoca un enfrentamiento para con las mujeres de la familia; por otro lado, también lo causa el hecho de que la Tercera Hija salga del espacio familiar, puesto que dará pie a una segunda forma de traición al entablar una relación sentimental con uno de los soldados. Por último, la salida de la Segunda Hija representará otra forma de conflicto, en el sentido en que su estancia en el afuera dará pie a que abandone sus orígenes y adopte voluntariamente la fe cristiana, renegando de la creencias familiares, ancestrales. Con la Niña ocurre algo distinto, que irá directamente ligado a la configuración del personaje; ella sí está autorizada a salir y entrar del espacio familiar en tanto va y vuelve de la escuela, y será además ella la que saldrá definitivamente de la casa, como resultado de una decisión racional. Más allá, y como se expondrá en adelante, es precisamente

5 El tratamiento mítico de la mujer malvada en términos de genealogía familiar femenina ha sido abordado por la crítica en trabajos como los de Milagros Palma (1991: 144-145) y Luísa Lagoeiro (2015: 196196). 
la Niña la única mujer de la casa que no es una Malinche, y no casualmente la única, como ella misma averiguará, cuyo padre no es un indígena sino un conquistador.

No ocurre lo mismo con los hombres, cuya entrada a la casa se representa en términos positivos en el caso, por ejemplo, del Extranjero. Además, su presencia - siendo hombre, conquistador - en ese "adentro" servirá progresivamente para desarticular - y desgeneralizar - la idea negativa del hombre conquistador. Con su presencia en el espacio de las mujeres, el extranjero se constituirá paulatinamente en figura de autoridad reconocida a través de distintas vías que se expondrán posteriormente.

\subsection{Muchas Malinches que son una sola}

Desde un primer momento, el título de la obra hace referencia directa a la Malinche, aunque ninguno de los personajes tenga nombre de pila. Sin embargo, no es una única Malinche la que aparece, sino que la figura de la mujer traidora, unida a distintos referentes que apuntan al discurso de la Historia acerca de tal personaje, se construye a partir de una multiplicidad de mujeres, todas ellas indígenas y pertenecientes a la misma familia. De este modo, tanto la Madre como las tres hijas mayores cumplen con alguno de los rasgos con los que la crítica ha etiquetado a la Malinche o sus acciones para con Hernán Cortés y la conquista de México. Es por ello que podemos pensar que, de alguna forma, la etiqueta de Malinche, con todos los significados que arrastra, se extiende a un plano colectivo que abarca el perímetro de las mujeres indígenas, y que excluye a la Niña en tanto es fruto del mestizaje.

Nos hallamos, pues, ante cuatro mujeres que se señalan las unas a las otras como culpables de traición, pero que todas ellas a la vez cometen la falta de la traición. En su conjunto componen, por así decirlo, una figura poliédrica que encaja todas las piezas del mito. En la mayoría de ellas, además, el motivo del amor o deseo hacia el conquistador se muestra de nuevo como desencadenante de la acción traidora, acción que las condenará como responsables de alguna culpa. Es posible concebir, sobre esta base, la representación múltiple de la Malinche a través de los diversos personajes femeninos de la familia como una forma de poder leer esas distintas versiones de la Malinche que se han construido históricamente en los diferentes discursos que se han producido sobre ella. 
En principio, todas ellas parecen presentarse como sujetos fuertes, capaces de defender ese espacio propio en que se inscribe su identidad; varias son las referencias que aluden al hecho de su voluntad de lucha para evitar la conquista. Con todo, esa identidad a priori fuerte se verá resquebrajada casi siempre a partir del mismo recurso: el amor o el deseo hacia el hombre conquistador.

Tanto las tres hijas mayores como la Madre son traidoras, y en esa línea hablábamos del modo en que las características de la Malinche en tanto modelo de mujer es un posible aplicable a "las mujeres" entendidas en términos de generalidad. Pero no solamente son traidoras, sino que además configuran todas ellas - excepto la Niña - personajes cuyos actos entran en contradicción con sus discursos, y cuya identidad se vuelve inestable al entrar en contacto con algún elemento del imaginario del conquistador -sea el hombre, sea el saber occidental-, siempre entendido en términos de objeto de deseo. Por otro lado, este elemento desestabilizador no lo es solo de sus entidades individuales sino también de las relaciones materno-fraternales que existen entre ellas como presupuesto, pues los diálogos que entablan van alternativamente del reproche y la amenaza a la comprensión empática. Podríamos decir que, de alguna forma, dicho motivo amoroso las acaba debilitando en comparación con esa fortaleza primera que presentaban.

¿Cómo se plantea la cuestión de la maternidad? Los personajes nucleares de la obra son, efectivamente, cuatro hijas y su madre. Sin embargo, la entidad hija mestiza funciona en la obra de forma diferente a la de hija indígena. Como se ha visto, los enfrentamientos entre las hijas mayores y la Madre se hacen patentes a lo largo de la obra, y se comprueban en hechos como el de que la Madre incluso llegue a ofrecer como tributo ${ }^{6}$ al capitán a la hija mayor a cambio de que cese los ataques, o en el modo en que también la Madre acu-

6 Según el ya citado trabajo de González Hernández (2002: 11), la Malinche habría sido ofrecida como tributo a Cortés, junto con otras mujeres y objetos. En una síntesis de los trabajos de Gayle Rubin, Girona (2008) expone: «La autora parte de la teoría de los sistemas de parentesco y el concepto de intercambio como principio organizador de la sociedad, en donde la mujer es el "don" más preciado, y en donde advierte una asimetría: entre los que intercambian y lo intercambiado, no solo en la medida en que los varones tienen derechos sobre las mujeres sino también en la medida que ellas no optan a ese mismo derecho; esa asimetría tiene asegurada la dependencia de un sexo sobre otro, pues desde el momento en que la mujer es el objeto de intercambio, y no una de las partes se transforma en el signo de algo, y ello implica un conjunto de imposiciones, prohibiciones, obligaciones y derechos diferenciales para ellas, en relación con los hombres». (2008: 88) 
sa y culpa abiertamente a sus hijas en distintas ocasiones. En contraste con ello, por una parte la Niña no participa de tales enfrentamientos, en cierto modo porque, como se expondrá más adelante, posee una cierta superioridad ética con respecto a las demás, asociada a las ideas de progreso y la civilización que radica en el hecho de que su padre no sea un indígena sino uno de los conquistadores.

En cuanto a las nociones de "traición" y "culpa", que son dos de los atributos más potentes del mito, se aprecia cómo las diversas Malinches de esta obra se traicionan constantemente entre ellas, pero generalmente no asumen "sus culpas". Por el contrario, son capaces de detectar la culpabilidad en cualquiera de las otras, pero nunca en ellas mismas. Sobre esta base, encontramos en las hermanas de nuevo personajes contradictorios, con una conducta que se acerca a rasgos como la hipocresía o el engaño, en contraposición con el Extranjero, que se muestra honesto y autocrítico.

Entre las múltiples reescrituras literarias de la Malinche rescato en este punto la de Elena Garro, en concreto en el relato La culpa es de los tlaxcaltecas (1989). En ella se realiza un trabajo verdaderamente profundo con estas dos nociones, que plantea y se cuestiona de forma insistente acerca de si es posible resignificar estos atributos reapropiándose de ellos. No es el caso, en cambio, del texto que ocupa el presente análisis, en que la traición propia no se reconoce $\mathrm{o}$, si se reconoce, se hace achacándolo a la irracionalidad del amor o deseo hacia el conquistador. Es lo que ocurre, por ejemplo, en el momento en que la Hija Mayor reconoce haber traicionado a sus hermanas y madre y pensemos, más ampliamente, también esta como una traición hacia su cultura y su comunidad. En cuanto ella achaca su culpa al deseo por el conquistador, es perdonada por su madre, y se trata de un acto que no debe pasar desapercibido si se presta atención a las formas contemporáneas de reescritura de la Malinche, en las cuales uno de los focos fundamentales se centra en la oscilación entre la culpabilización y la exculpación de esa falta que históricamente se atribuye al personaje $\mathrm{e}^{7}$ y que es uno de los ejes princi-

\footnotetext{
7 Milagros Palma (1991), en una aproximación a la obra de Galeano Memorias del fuego: los nacimientos, comenta: «Hoy, con más fuerza que nunca, sólo el poder diabólico de una mujer puede explicar la caída del poderosísimo imperio azteca. La vanidad masculina impide poner en tela de juicio su gestión totalitaria del mundo, su despotismo, sexismo y racismo» (1991: 143). Con ello, muestra cómo cierto sector de la crítica se ha servido de mistificaciones de la feminidad para justificar los hechos, en este caso, de la Conquista.
} 
pales de su construcción mítica. En estos discursos, el amor o deseo hacia el conquistador sirve como pretexto, bien para la culpabilización, como ocurre con las ya citadas palabras de Octavio paz (1998), bien para la exculpación, como plantea al igual que la obra de Stranger ${ }^{8}$ (2012) el relato La culpa es de los tlaxcaltecas, de Elena Garro (1989).

\subsection{La figura del conquistador}

Si el espacio propio de las mujeres era la casa, ese "adentro" privado la salida del cual era desencadenante de conflictos, el espacio en que estos se mueven es un indeterminado "afuera", bajo la premisa de querer acceder a ese territorio propio del otro.

Tal y como se ha expuesto, las hermanas mayores y la Madre, en tanto formas diversas de encarnar el modelo de la Malinche, adquieren un carácter unidimensional, del que solo se salvará la Niña. Por el contrario, al observar a las figuras del Capitán y del Extranjero, es posible establecer las múltiples diferencias que, pese a partir de una misma premisa inicial, los distancian a ojos del lector. Como resultado, del texto se desprende el hecho de que, mientras que los hombres - occidentales- son susceptibles de singularización, es posible reducir a las mujeres - indígenas - a un patrón único. Mientras que el Extranjero es humilde, comprensivo y sincero, el Capitán es violento y despiadado. En las diferencias entre ambos, pues, radica la posibilidad de sabotear la visión negativa del conquistador, algo que contextualmente juega en contra de la voluntad de desmitificar a la Malinche.

Así pues, la forma en que se profundiza poco a poco en el personaje del Extranjero a medida que las mujeres le permiten el acceso a su espacio privado tiene como consecuencia el hecho de que estas lo acaben reconociendo como autoridad ética e intelectual. Ética, por un lado, porque muestra humildad y un sentimiento autocrítico para con su antiguo bando - es un desertor-, pero sobre todo al comparar su discurso de sinceridad con la actitud hipócrita de la Hija Mayor en la sexta escena -acusa de traición pero no reconoce la suya-; al visitar a sus hermanas, tiene constancia de que están protegiendo al Extranjero y expone a estas las causas por las que el Extranjero debe volver

8 El tema se aborda sucinta aunque particularmente en «El discurso femenino en el teatro de Inés M. Stranger o amar a quien no se debe» (Diago, 1995). 
con el Capitán, para lo que lo acusa de traidor: «A eso se le llama traición... Ellos han venido desde muy lejos para combatir juntos... No pueden abandonarse. Él no es el primer soldado que se pasa al enemigo [...].» (2012: 14)

La autoridad intelectual del Extranjero, en tanto portador de un saber verdadero ${ }^{9}$, el saber occidental (incluso pese al hecho de ser analfabeto) es confirmada primero por la Niña - paradigma de la racionalidad en la familia y por las demás hermanas, e incluso al final indirectamente por la Madre, quien, vencida por la civilización, se deja morir «retrocediendo a su lengua» (2012: 24). Desde la perspectiva de la Niña, es posible establecer una comparación entre el motivo de los deberes de la escuela en la primera escena, situación que escapa a la comprensión de la Madre, y el modo en que el tema resurge en la escena séptima, cuando la Niña le pide al Extranjero no que la ayude sino que sancione su conocimiento, en tanto precisamente autoridad "naturalmente" portadora de ese conocimiento válido.

\subsection{Si olvidamos la masacre, el mestizaje es esperanza.}

Como se ha expuesto en apartados anteriores, tanto la madre como las tres hijas cumplen con ciertas de las características que históricamente se le atribuyen a la Malinche, de forma que sus personajes quedan aunados en torno a ese núcleo. En cambio, el personaje de la Niña muestra un contrapunto frente al resto de mujeres. Ella no es hija del mismo padre que las demás hermanas sino de uno de los conquistadores, si bien es un dato que no sale a la luz hasta la mitad de la obra. Es esa información la que da sentido al espacio que separa a niña y madre, ejemplificado en los primeros diálogos del texto:

- ¿La palabra "anhelo" se escribirá con " $\mathrm{h}$ "?

- No lo sé hija, Qué sé yo de todo eso.

- Bueno, no importa... la h no suena.

- ¿No suena?

9 Foucault, en referencia a lo que llama "los efectos de verdad que el poder produce y transmite", dice: «No hay ejercicio de poder posible sin una cierta economía de los discursos de verdad que funcione en, a partir de y a través de esta culpa: estamos sometidos a la producción de la verdad del poder y no podemos ejercer el poder sino a través de la producción de la verdad». (2006: 27-28) 
- No. La h es muda.

La madre se detiene. No comprende.

- ¿Muda? ¿Existe una letra muda?

La niña se ríe. La madre se ríe con ella.

- Todas las letras son mudas para mí. (2012: 2)

Se trata de una escena en la que se da cuenta de que la madre es incapaz de responder, sobre todo a nivel intelectual, a las incógnitas que la Niña le plantea. Esta se configura como un personaje inteligente, a quien le es posible ver más allá del silencio de su madre y que toma determinaciones conscientes, como ocurre con su decisión final. Frente al carácter volátil y pasional de sus hermanas, ella se decanta siempre hacia el terreno de lo racional. Al fin y al cabo, en tanto única mujer de la casa que escapa a los atributos de la Malinche como estereotipo negativo de mujer, personifica algún tipo de esperanza. Pero, ¿esperanza para quién? En este punto el análisis se relaciona con la línea de crítica que ve a la Malinche como fundadora de la mexicanidad en términos de mestizaje ${ }^{10}$, en principio en un sentido positivo, sustentada por el hecho de que esta diera a luz a un hijo de Cortés.

Si bien es cierto que el monólogo final de la Niña trata de dignificar la memoria de su madre y, por extensión, la de las mujeres de su familia, poniendo en tela de juicio el discurso de la Historia, por una parte lo hace desde un lugar que raya en el paternalismo y, por otro, retorna al tópico del amor-deseo como elemento exculpador y, con ello, confirma la identidad pasional de dichas mujeres.

\section{DESPUÉS DE TODO, ¿QUÉ QUEDA DE LA REESCRITURA?}

A la luz de lo expuesto, es posible deducir que esta obra de I. Stranger, si bien pretende dar pie a la reflexión por cuanto ofrece distintos posiciona-

10 T. Todorov, que dedica toda su obra La conquista de América. El problema del otro a cuestionar la lectura occidental del proceso de la conquista, participa de esta línea apuntando lo siguiente: «es cierto que la conquista de México hubiera sido imposible sin ella (o alguien que desempeñara el mismo papel), y que por lo tanto es responsable de lo que ocurrió. Yo, por mi parte, la veo con una luz totalmente diferente: es ante todo el primer ejemplo, y por eso mismo, el símbolo, del mestizaje de las culturas» (1998: 123). 
mientos encarnados por los diversos personajes, que enfrentan sus vivencias y su relato de los hechos a través del diálogo, la recuperación que se hace en él del mito de la Malinche recae constantemente en retóricas que privilegian el saber occidental frente a la epistemología indígena, y perpetúa y reafirma una imagen de la mujer asociada a la sentimentalidad y al terreno de lo irracional. Además, el tratamiento que se hace del tópico de la traición no hace sino reforzar una visión unidimensional de la mujer que, irónicamente, es incapaz de ver que las mujeres que las rodean son iguales a ella. Al fin y al cabo, sus posicionamientos no quedan alejados de la línea de crítica que esboza Octavio Paz; se da, en definitiva, el reconocimiento de la traición y una exculpación por la vía amorosa, algo a lo que también apunta el autor al hablar de su "fascinación" hacia el conquistador. Se trata de una idea que se repite en algunos trabajos que abordan la reescritura de la mujer indígena, como es el caso de Hoppe (2011), en relación en este caso con el relato “De brujas y de mártires" en la obra Frutos extraños (2006) de Lucía Guerra. En su análisis, habla de que

la figura de la mujer indígena como signo de sumisión, de no resistencia e, incluso, de fascinación por la presencia del otro (europeo) [...] ha habitado no solamente en los libros de historia como en buena parte de la literatura y, de cierta forma, el imaginario colectivo. (2011: 7)

En este punto, cabe recordar la acertada conceptualización de América desde la mirada del conquistador que perfila De Certeau en el prólogo a $\mathrm{La}$ escritura de la Historia (1999) en relación con un grabado de Jan Van der Straet que se reproduce en la edición francesa de la obra (1975):

Amerigo Vespucci el Descubridor llega al mar. De pie, y revestido con coraza, como un cruzado, lleva las armas europeas del sentido y tiene detrás de sí los navíos que traerán al Occidente los tesoros del paraíso. Frente a él, la india América, mujer acostada, desnuda, presencia inominada de la diferencia, cuerpo que despierta entre un espacio de vegetaciones y animales exóticos. Escena inaugural. Después de un momento de estupor en ese umbral flanqueado por una columna de árboles, el conquistador va a escribir el cuerpo historiado -el blasón- de sus trabajos y de sus fantasmas. Ella será América "latina". (1999: 11)

A modo de conclusión, si la Malinche fue un chivo expiatorio de la Historia que permitió fundar determinadas nacionalidades en base a ciertos intereses 
políticos y económicos, no cabe por ello olvidar el modo en que su figura circula en el imaginario colectivo tanto a nivel general como intersubjetivo, y cómo se plasma y recupera en diferentes productos culturales. Así, la autora de la obra escogida no escapa tampoco, en su intento de reescribir y subvertir al personaje, de recaer en determinadas contradicciones que vuelven, de alguna forma, a inscribir a la Malinche en una línea que hace de ella de nuevo una mujer débil, frágil, ignorante o indefensa. Sobre esta base, varias propuestas similares oscilan entre la "exculpación" de la Malinche a cambio de justificaciones que la acercan a la sentimentalidad y a la victimización, o bien una cierta reivindicación de la propia traición que le permite reapropiarse positivamente de su estigma pero que, como consecuencia de ello, mantiene su condición de traidora. Para subvertir culturalmente estos referentes es necesaria una labor rigurosa que no se limita a la intencionalidad, sino que exige toda una revisión de los presupuestos sobre los que se trabaja y una ineludible lucidez crítica.

\section{REFERENCIAS BIBLIOGRÁFICAS}

Albadalejo López, Ana (2016), Tras las huellas de (La) Malinche. Tránsito del arquetipo en el teatro mexicano de la segunda mitad del siglo $x x$, Tesis doctoral inédita, Valencia, Universitat de València, Facultad de Filología, Traducción y Comunicación. En línea: https://www.educacion.gob.es/teseo/ imprimirFicheroTesis.do?idFichero=KF8LMHs19JM\%3D. Último acceso el 13-ene-2019.

Berman, Sabina (1984), «Águila o sol», en Teatro de Sabina Berman, México, Editores Mexicanos Unidos, págs. 223-250.

Bravo Elizondo, Pedro (1996), «Una entrevista con Inés Margarita Stranger (Chile) y sus personajes femeninos», en Latin American Theatre Review, 30, 1, págs. 89-96.

ButLER, Judith (2002), Cuerpos que importan. Sobre los limites materiales y discursivos del "sexo", Buenos Aires, Paidós.

Castellanos, Rosario (1975), El eterno femenino: farsa, México, Fondo de Cultura Económica. 
De Certeau, Michel (1999), La escritura de la Historia, México, Instituto Tecnológico y de Estudios Superiores de Occidente (ITESO).

- (1975), L'écriture de l'histoire, París, Éditions Gallimard.

Derrida, Jacques (2014), Posiciones. Entrevistas con Henri Ronse, Julia Kristeva, Jean-Louis Houdebine y Guy Scarpetta, Valencia, Pre-Textos.

Diago, Nel (1995), «El discurso femenino en el teatro de Inés M. Stranger o amar a quien no se debe», en Sonia Mattalía y Milagros Aleza Izquierdo (coords.), Mujeres, escrituras y lenguajes: (en la cultura latinoamericana y española), Departamento de Filología Española, Facultad de Filología, Universitat de València, págs. 84-87.

Díaz del CASTILlo, Bernal (2011), Historia verdadera de la conquista de la nueva España, edición de Guillermo Serés, Barcelona, Galaxia Gutenberg: Círculo de Lectores.

Esquivel, Laura (2006), Malinche, Barcelona, Santillana.

Foucault, Michel (2006), Genealogía del racismo, La Plata, Altamira.

Garro, Elena (1989), La culpa es de los tlaxcaltecas, México, Grijalbo.

Girona Fibla, Núria (2008), Rituales de la verdad. Mujeres y discursos en América Latina, París, RILMA/ ADEHL.

GlantZ, Margo (2001), «La Malinche: la lengua en la mano», Biblioteca Virtual Miguel de Cervantes. En línea: http://www.cervantesvirtual. com/obra-visor/la-malinche---la-lengua-en-la-mano-0/ html/ 6daba5d3-e7eb-42c0-b258-a77fb077a952_7.html. Último acceso el 20-nov2018.

GonzÁlez Echevarría, Roberto (2000), Mito y archivo. Una teoría de la narrativa latinoamericana, México, FCE.

GonzÁlez Hernández, Cristina (2002), Doña Marina (la Malinche) y la formación de la identidad Mexicana, Madrid, Ediciones Encuentro.

GorostizA, Celestino (2004), «La Malinche o La leña está verde», en Teatro completo, México, INBA, págs. 465-544. 
Guerra, Lucía (2006), Frutos extraños, Santiago, Cuarto propio.

Hall, Stuart (1992), «Occidente y el resto: discurso y poder». En línea: https:/ / www.coursehero.com/file/13608987/Hall-Occidente-y-el-Resto-1/. Último acceso el 30-jun-2018.

- (2003): «¿Quién necesita identidad?» en Stuart Hall y Paul Du Gay (ed.), Cuestiones de identidad cultural, Buenos Aires, Amorrortu, págs. 13-39.

Hoppe Navarro, María (2011), «El mito de la Malinche en la obra reciente de escritoras hispanoamericanas», en Mitologías hoy: Revista de pensamiento, crítica, y estudios literarios latinoamericanos, 4, págs. 5-14. En línea: http:// revistes.uab.cat/mitologias/article/view/v4-hoppe/14. Último acceso el 10-sep-2018.

Lagoeiro Ferreira, Luísa (2015), «Griselda Gambaro, Inés Margarita Stranger, Maria Adelaide Amaral e a dramatúrgia femenina na América Latina da dècada de 1990», en Revele: Revista Virtual dos Estudantes de Letras, 8, págs. 187-203.

O'Gorman, Edmundo (2006). La invención de América, México, Fondo de Cultura Económica.

Palma, Milagros (1991), «Malinche, el malinchismo o el lado femenino de la sociedad mestiza», en L. Luna (comp.), Género, clase y raza en América Latina, Seminario Interdisciplinario de Mujeres y Sociedad, Barcelona, Universitat de Barcelona, págs. 131-164. En línea: http://www.ub.edu/ SIMS/pdf/GeneroClaseRaza/GeneroClaseRaza-04.pdf. Último acceso el 12-ene-2019.

PAz, Octavio (1998), El laberinto de la soledad, Madrid, Fondo de Cultura Económica de España.

SPIVAK, Gayatry C. (2009), ¿Pueden hablar los subalternos?, Barcelona, Publicacions del Museu d'art contemporani de Barcelona (MACBA).

Stranger, Inés M. (2012), Malinche. Buenos Aires: CELCIT (Centro Latinoamericano de Creación e Ivestigación Teatral. En línea: https://www.celcit.org.ar/bajar/dla/375/. Último acceso el 30-jun-2018. 
- (2007), Malinche. Cariño malo. Tálamo, Chile, Cuarto Propio.

Todorov, Tzvetan (1998), La conquista de América. El problema del otro, México, Siglo veintiuno editores.

Usigli, Rodolfo (1983), Corona de sombra; Corona de fuego; Corona de luz, México, Porrúa.

VAn der Straet, Jan (1587-89), Discovery of America: Vespucci Landing in America, Nueva York, Metropolitan Museum of Art (MET), En línea: https:/ / www.metmuseum.org/art/collection/search/343845. Último acceso el 15-sep-2018. 


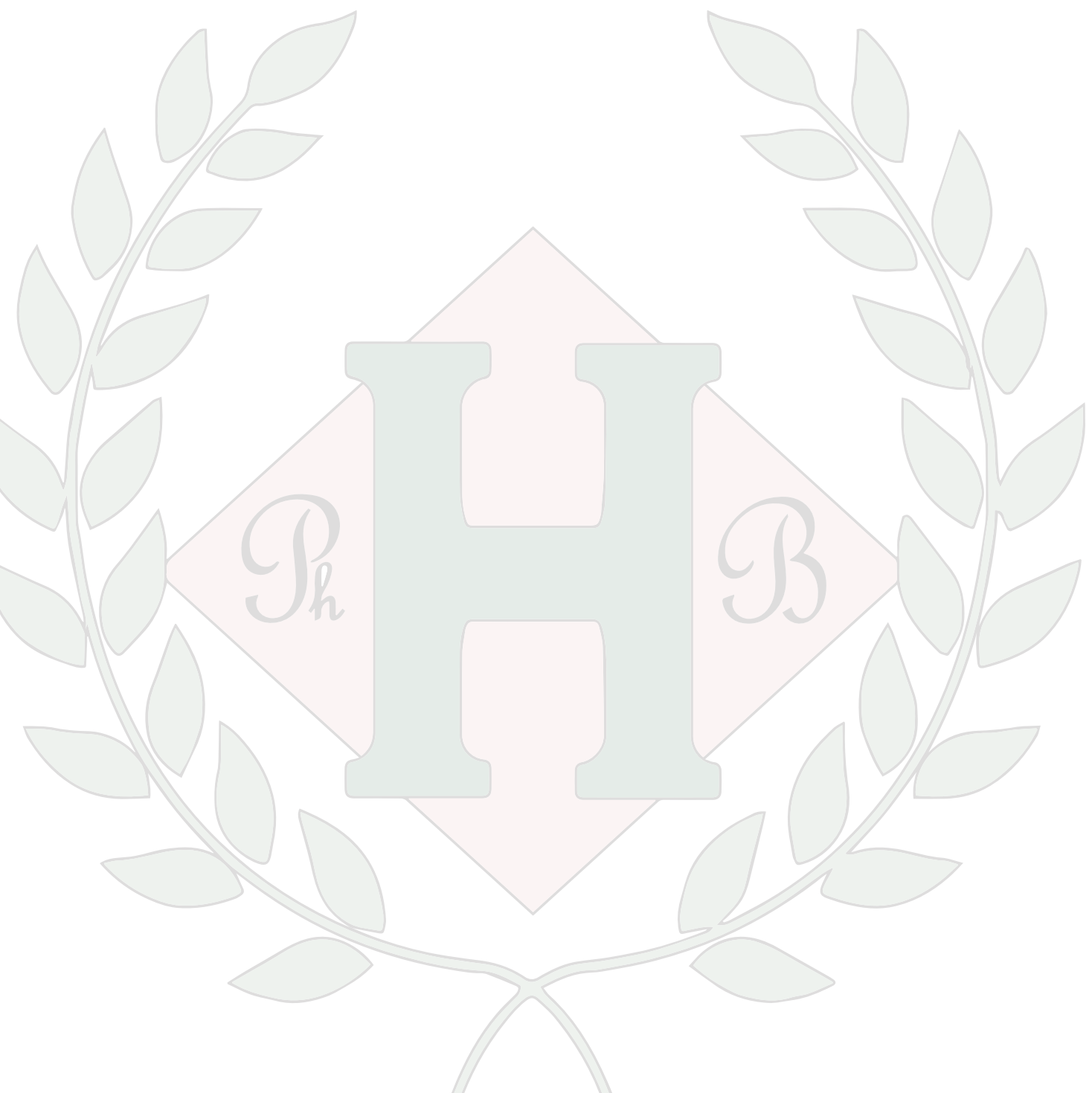

